\title{
College Students' Academic Achievement: \\ Exploring the Role of Hope and Academic Self-Efficacy
}

\author{
Esther C. Penzar ${ }^{1}$, Munyi Shea ${ }^{2}$, and Cher N. Edwards ${ }^{2}$ \\ ${ }^{1}$ Bellevue School District \\ ${ }^{2}$ Seattle Pacific University
}

\begin{abstract}
In the present study, the relationships among trait hope, academic self-efficacy, and academic achievement (self-reported GPA) were examined among college students. Demographic differences were analyzed based on college-going status, ethnicity, and gender. First-generation college-going students (FGCS) reported significantly lower levels of trait hope, academic selfefficacy, and academic achievement when compared to non-FGCS. Male students reported significantly lower academic self-efficacy compared to female students. There was no statistically significant difference between non-White and White students. Overall, academic self-efficacy was a stronger predictor of achievement than hope. Between the two subscales of trait hope, agency was more strongly correlated with academic achievement than pathways. Furthermore, a mediation analysis indicated that academic self-efficacy fully accounted for the relationship between agency and academic achievement, which suggests that perceived capacity and agency to perform tasks in a specific domain may be more strongly associated with academic achievement than a general sense of hope and motivation.
\end{abstract}

Keywords: first-generation college students, trait hope, academic self-efficacy, academic achievement, agency

Author Note

Esther C. Penzar (iD) https://orcid.org/0000-0003-1338-9994

Munyi Shea (D) https://orcid.org/0000-0002-0273-4038

Cher Edwards (iD) https://orcid.org/0000-0003-1908-8682

We have no known conflict of interest to disclose.

Correspondence concerning this article should be addressed to:

Dr. Munyi Shea, 3307 3rd AVE W, Seattle WA 98119. Email: mshea@spu.edu. 


\section{College Students' Academic Achievement:}

\section{Exploring the Role of Hope and Academic Self-Efficacy}

The rate of college enrollment has steadily increased in the United States over the past decade. There were approximately 16.6 million undergraduate students enrolled in degreegranting postsecondary institutions by the end of 2018, a 26\% increase since 2000 (Hussar et al., 2020). Of those 16.6 million college students, about $52.4 \%$ identified as White, $20.5 \%$ as Hispanic, $12.7 \%$ as Black, $6.7 \%$ as Asian, and a smaller percentage of students as Native American, Pacific Islander, or two or more races. Although there is an overall increase in postsecondary enrollment and degree attainment in the U.S., there continue to be disparities across racial/ethnic backgrounds, gender, and college-going status (Cataldi et al., 2018; Snyder et al., 2019). For example, college graduation rate tends to be higher for female students, White students (National Center for Education Services, 2019), and college students whose parents also attended or completed college (Cataldi et al., 2018).

First-generation college-going students (FGCS) are defined as college students whose parents did not attend college or attain a bachelor's degree (Jehangir, 2010). FGCS constitute approximately $30-50 \%$ of the undergraduate population in the United States (Snyder et al., 2019) and are overrepresented by students from marginalized, non-White, or lower-income groups (Chen \& Carroll, 2005; Ishitani, 2006; Tate et al., 2015). Research has shown that FGCS tend to face a myriad of challenges as they pursue a college degree. When comparing postsecondary enrollment rates among FGCS and non-FGCS, 72\% of FGCS enrolled in postsecondary institutions whereas $93 \%$ of continuing-generation students enrolled in postsecondary institutions (Cataldi et al., 2018). Research shows that even when other demographic background (e.g., income) and college (e.g., academic preparation) factors are controlled for, FGCS status is still significantly correlated with a lower GPA (Strayhorn, 2010). In sum, FGCS stands out as a unique risk factor for college students in terms of college access, persistence, and postsecondary outcomes (Cataldi et al., 2018; Chen \& Carroll, 2005; Ishitani, 2006).

The positive effects of hope have been studied over the past decades in relation to psychological well-being and academic achievement (Gilman et al., 2006; Snyder et al., 2003). Past research has highlighted that hope uniquely and positively contributes to college students' academic achievement (Gallagher et al., 2017; Snyder et al., 2002) and psychological well-being (Gilman et al., 2006; Snyder et al., 2003). Specifically, students with a higher level of hope tend 
to have higher academic success, even after controlling for other psychological and cognitive factors, including optimism, self-efficacy, intelligence, and engagement (Day et al., 2010; Gallagher et al., 2017).

One of the major critiques on positive psychology research, however, is the underrepresentation of disfranchised populations in the samples, and the relatively scant attention to issues relevant to race, ethnicity, and gender (Rao \& Donaldson, 2015). Hope research has yet to be applied to first-generation college students. The present study sought to examine how trait hope as a cognitive-motivation system, alongside academic self-efficacy, a related cognitive construct, may impact college students' academic achievement at the intersection of their race/ethnicity, gender, and college-going status.

\section{Theoretical Constructs of Hope and Academic Self-Efficacy}

\section{Hope Theory}

Hope theory arose formally from the field of positive psychology through the work of C.R. Snyder and his colleagues in 1991. Hope theory was created under the notion that individuals are goal-oriented and hold internal goal-directed cognitions and motivations to meet those goals (Snyder \& Lopez, 2005). These goal-oriented thoughts also include the perceived success or failure of the goal and the emotions that result from the goal attainment process. Hope is more than a simple goal-directed pursuit; rather it is a cognitive-motivational system directed towards goal attainment. A cognitive-motivational system can be understood as a reciprocal system dependent on the successful exchange between agency (goal-directed determination) and pathways (planning of ways to meet goals) (Snyder et al., 1991). Hope theory attributes goal-directed behavior to underlying beliefs about oneself, with agency and pathways as prerequisites to motivation in goal attainment (Snyder et al., 2002).

Hope and related internal psychological factors have been recognized in recent years as stronger factors than cognitive aptitudes such as intelligence, prior academic achievement, and standardized test scores, in predicting college-level academic achievement (Day et al., 2010; Feldman \& Kubota, 2015). C.R. Snyder and colleagues (2002) conducted a 6-year longitudinal study among college students investigating the associations between their individual level of hope (measured by the Trait Hope Scale), cumulative GPA, retention, and graduation rate. The Trait Hope Scale scores were significantly and positively correlated to students' cumulative GPA measured at the end of the first semester and continued to demonstrate a significant relationship 
to students' GPA at the end of the second semester. Conversely, students endorsing lower levels of hope had significantly lower GPAs even as early as the first semester and were less likely to graduate college compared to their counterparts. In their longitudinal study, Snyder and colleagues concluded that hope and cumulative GPA were significantly and positively correlated. Furthermore, after controlling for other related intrapersonal factors such as personality, selfefficacy, optimism, divergent thinking, and academic engagement, hope was still found to uniquely and positively predict college students' academic achievement, including their cumulative GPA and graduation rates (Day et al., 2010; Gallagher et al., 2017).

\section{Academic Self-Efficacy}

Self-efficacy shares similar properties with hope as both are considered cognitive-focused approaches within the field of positive psychology. Self-efficacy was examined previously alongside hope to determine their combined and unique impact within academic settings (Feldman \& Kubota, 2015; Gallagher et al., 2017; Snyder et al., 2002).

The construct of self-efficacy stemmed from Social Cognitive Theory (SCT) and was introduced by Bandura (1977). SCT proposed that people are agentic beings capable of influencing their own functioning and shaping the course of environmental events. In this view, people are contributors to their life circumstances rather than passive products of them (Bandura, 1977; Snyder \& Lopez, 2005). Self-efficacy is not a skill or generalized trait, rather it is a cognitive process that develops over time based on individuals' experience, reflection, and evaluation of those experiences (Snyder \& Lopez, 2005).

While trait hope refers to an individual's positive motivational state that constitutes a sense of agency (i.e., goal-directed energy) and perceived pathways/resources (i.e., ways to reach the goals) (Snyder et al., 1991), self-efficacy measures an individual's belief in his or her capacity to conduct certain actions in order to achieve the desired outcomes in a specific context (Bandura, 1977; Snyder et al., 1991; Snyder \& Lopez, 2005). Academic self-efficacy is a term specifically referring to individuals' perception of their capacity to achieve desired outcomes by successfully performing certain tasks in the academic domain. These tasks may include prioritization of assignments and projects, note-taking, test-taking, writing, and research competency (Chemers et al., 2001). In short, trait hope is a positive dispositional state that captures a person's motivation to intitiate and maintain a goal (the will and the determination), 
whereas self-efficacy captures one's perceived capacity in carrying out certain actions to achieve the stated goal in a more specific context.

\section{Relationship between Hope and Academic Self-Efficacy}

Empirical studies further examined and supported the significant relationship between hope and self-efficacy. For example, a study by Atik and Zeynep (2017) on 392 Turkish high school students reported a significant relationship between hope and academic self-efficacy. Specifically, they found that academic self-efficacy was more closely related to the agency rather than the pathways component of hopeful thinking. Feldman and \& Kubota (2015) examined the role of trait hope, academic hope, general self-efficacy, academic self-efficacy, and academic achievement (as measured by GPA) among undergraduate students. They found that trait hope predicted GPA through domain-specific constructs, such as academic hope and academic selfefficacy. On the contrary, general self-efficacy had a much weaker correlation with GPA than trait hope. Gallagher and colleagues (2017) reported similar findings based on their study of over 200 undergraduate students. They found that while academic self-efficacy and engagement were all correlated with college students' GPA and retention, academic specific hope positively and uniquely predicted GPA, above and beyond the effect of prior academic achievement (i.e., education history) and academic self-efficacy.

Altogether, these findings suggest that academic self-efficacy plays an important role in college students' academic achievement, yet hope remained a unique and robust predictor of academic achievement above and beyond the effect of academic self-efficacy (Feldman \& Kubota, 2015; Gallagher et al., 2017). Furthermore, trait hope may influence academic achievement through domain-specific variables such as academic self-efficacy. As such, the present study sought to examine the combined and unique predictive effect of trait hope and academic self-efficacy on college students' academic achievement, as measured by their GPA. In addition, academic self-efficacy was included as a mediator in the path analysis to determine if and how academic self-efficacy may account for the relationship between trait hope and academic achievement.

\section{Summary of Research Questions}

Hope research has yet to be applied to first-generation college students. However, based on the significant association shown between hope and academic achievement in prior reearch, hope could be considered a potential protective factor for FGCS. Hence, the present study sought 
to explore whether there are significant differences in the levels of trait hope, academic selfefficacy, and academic achievement between first-generation college students and continuinggeneration college students. Other demographic differences such as racial/ethnic identification

and gender self-identification were examined. Our research questions are summarized as follows:

1. Are there demographic differences (racial/ethnic, college-going status, and gender) among the three variables hope, academic self-efficacy, and self-reported GPA?

2. What are the relationships between trait hope, academic self-efficacy, and academic achievement as measured by self-reported GPA among college students?

3. Which factor of trait hope - agency or pathways - would be a stronger predictor of academic achievement as measured by self-reported GPA among college students?

4. Does academic self-efficacy mediate the relationship between agency and academic achievement?

\section{Method}

\section{Participants and Procedure}

Approval was received from the authors' Institutional Review Board to recruit student participants. A total of 316 participants were recruited from a private university on the West Coast through the undergraduate psychology subject pool (International Undergraduate Services), co-curricular programs serving ethnically diverse students, and tabling events on campus. The inclusion criteria specified a minimum age of 18 and current enrollment in the university. The sample was predominantly female (70.9\% female, $26.6 \%$ male; $2.5 \%$ nonbinary, queer, non-conforming, or other), U.S. born (82.29\%), and tended to be younger in age (average age $=19.8$ years, $S D=2.32)$ and more junior in class standing $(43.3 \%$ first-year student $)$. In terms of racial/ethnic backgrounds, slightly more than half of the participants self-identified as White (51.6\%). The rest identified as American Indian or Native American (0.3\%), African American or African (0.3\%), Asian American/Pacific Islander (10.1\%), Latinx (14\%), and biracial/multiracial or other (24\%). Finally, $25 \%$ of the participants self-identified as FGCS. Participants completed the online survey via their personal computer or mobile device.

\section{Measures}

Demographic questions assessed a participant's age, year in college, gender identification, racial/ethnic identification, highest degree aspiration, and college-going status (e.g., FGCS or non-FGCS). One question asked participants to report their current cumulative 
GPA. In prior studies, self-reported GPA was often used by researchers to determine academic achievement when the actual GPA was difficult to obtain. Self-reported GPA has been shown to have high correlations with students' actual GPA (Cassady, 2001). Thus, self-reported GPA was used in the present study as an indicator of students' academic achievement.

General measures of self-efficacy have not proven to be useful compared to specific selfefficacy measures in domains. Therefore, the Academic Self-Efficacy Scale (Chemers et al., 2001) was used to understand participants' perceived agency and capcity in performing necessary tasks in the academic domain. The Trait Hope Scale developed by Snyder and colleagues (1991) was used to assess our participants' level of hope. Scores for all measures were determined by averaging scores across all items. Higher scores indicate a stronger magnitude of the construct.

\section{Trait Hope Scale}

The Trait Hope Scale (THS; Snyder et al., 1991) consists of 12 items scaled from 1 (definitely false) to 8 (definitely true). In the initial study, the THS demonstrated high internal consistency: alpha coefficients ranged from .74 to .88 for the overall measure, .70 to .84 for the agency subscale, and .63 to .86 for the pathways subscale. Test-retest reliability for the overall scale ranged from an alpha of .85 over a 3 -week period to .82 over a 10 -week period (Snyder et al., 1991), and .74 for the pathways subscale and .81for the agency subscale (Snyder et al., 2002). In the present study, the alpha coefficients for the overall Trait Hope Scale, the agency and pathways subscales were $.85, .79$ and .77 , respectively. Example agency subscale questions include 'I energetically pursue my goals' and 'I meet the goals I set for myself.' Example pathways subscale questions include 'I can think of many ways to get the things in life that are most important to me' and 'There are lots of ways around any problem.'

\section{Academic Self-Efficacy Scale}

Chemers et al, (2001) developed the eight item Academic Self-Efficacy Scale (ASES) to measure participants' specific academic self-perceptions and skills. Items are rated from 1 (very untrue) to 7 (very true). Example questions include 'I am very capable of succeeding at the university,' 'I know how to study to perform on tests,' and 'I know how to take notes.' The ASES has demonstrated adequate internal consistency across various studies, ranging from an alpha coefficient of .81 (Chemers et al., 2001) to .84 (Gallagher et al., 2017). In the current study, the alpha coefficient was .82. 


\section{Results}

The first research question examined possible racial/ethnic, college-going status, and gender differences among all three variables (hope, academic self-efficacy, and academic achievement). Due to the small sample size in certain racial/ethnic groups, participants who identified as ethnic minorities constitute the non-White group, whereas participants who identified as biracial or multiracial but not White constitute the multiethnic group. Similarly, due to the very small sample size of participants who identified as gender non-binary or nonconforming, we only analyzed the data between female and male-identifying students. In sum, a one-way ANOVA was conducted for racial/ethnic groups (White, non-White and multiethnic), whereas an independent samples $t$-test analysis was chosen for evaluating the effect of collegegoing status (FGCS vs. continuing) and gender identification (male vs. female) on the three variables.

The homogeneity of variance was assessed by Levene's test for all three variables, and the academic self-efficacy variable met the assumption of equality of variance, $F(1,312)=2.49$, $p=.11$; however, self-reported GPA, $F(1,312)=4.89, p=.02$ and the hope variable did not meet the assumption, $F(1,312)=23.89, p<.001$. Welch's tests of equality of means were observed through the "equal variances not assumed" section to interpret the $t$-test results for the two variables that did not show homogeneity of variance. The bias-corrected bootstrapped confidence intervals were used to determine the genuine effect on the population for all variables in the groups that did not cross zero. Normality within groups was examined with a split file for FGCS and non-FGCS groups and displayed skewness and kurtosis within the minus one and plus one range for all three variables.

The independent samples $t$-test revealed a a statistically significant difference in hope levels, $t(312)=-2.72, p=.008,[\mathrm{BC}] 95 \% C I[-.708,-.111]$, academic self-efficacy, $t(312)=-$ $3.74, p<.001,[\mathrm{BC}] 95 \% C I[-.621,-.192]$, and academic achievement, $t(311)=-4.31, p<.001$, [BC] 95\% CI [-.360, -.133] between FGCS and continuing-generation students. Specifically, FGCS scored lower on all three variables: trait hope, academic self-efficacy, and academic achievement.

A one-way ANOVA was conducted to compare the effect of ethnicity (White, NonWhite, and multiethnic) on the variables hope, academic self-efficacy, and self-reported GPA. There was a statistically significant difference in trait hope $F(2,313)=3.76, p=.02$, academic 
self-efficacy $F(2,313)=16.234, p<.001$, and self-reported GPA $F(2,313)=26.31, p<.001$, across racial/ethnic groups. Hochberg's post hoc test revealed that non-White students scored significantly lower in hope (-.30) ( $p=.02)$, academic self-efficacy $(-.54)(p<.001)$, and selfreported GPA $(-.33)(p<.001)$ than White students. There were no statistically significant differences between multiethnic groups and White or non-White groups. Overall, the trends among non-White students and FGCS were similar: they both scored significantly lower in hope, academic self-efficacy, and self-reported GPA when compared to White students.

The institution from which we recruited the participants is predominately female, and our sample also reflected this trend. Gender group difference was only significant on one of the variables: academic self-efficacy, $F(4,311)=6.41, p<.001$. Hochberg's post hoc test revealed that men scored significantly lower in academic self-efficacy than women $(-.40)(p=.002)$.

Our second research question sought to understand the associations between trait hope (measured by agency and pathways), the agency subscale, academic self-efficacy, and college students' academic achievement (measured by self-reported GPA). A Pearson correlation analysis revealed positive, significant relationships among most variables (see Table 1). We followed Cohen's (1992) classification of effect sizes as small $(r=.10)$, medium $(r=.30)$, and large $(r=.50)$ to determine the effect size of these associations. Academic self-efficacy demonstrated a moderate correlation with trait hope $(r=.47, p<.01)$ and self-reported GPA $(r=$ $.45, p<.01)$, whereas trait hope showed a small correlation with self-reported GPA $(r=.18, p<$ .01). Our finding was consistent with the meta-analysis conducted by Marques et al. (2017), who reported that hope had an overall smaller correlation with academic achievement. Agency-a subfactor of trait hope-showed a stronger correlation with self-reported GPA $(r=.28, p<.01)$ than trait hope with self-reported GPA $(r=.18, p<.01)$. However, pathways - another subfactor of trait hope-was not significantly correlated with self-reported GPA, but was moderately correlated with academic self-efficacy $(r=.33, p<.05)$. In addition, agency demonstrated a strong correlation with trait hope $(r=.91, p<.01)$, and a moderate correlation with academic self-efficacy $(r=.53, p<.01)$. 


\section{Table 1}

Bivariate Correlations, Means, Standard Deviations for the Study Variables

\begin{tabular}{|c|c|c|c|c|c|c|c|}
\hline Measure & $M(S D)$ & Range & 1. & 2. & 3. & 4. & 5. \\
\hline 1. GPA & $\begin{array}{c}3.42 \\
(0.41)\end{array}$ & $0-4.00$ & - & $.18 * *$ & .038 & $.28 * *$ & $.45 * *$ \\
\hline 2. THScore & $\begin{array}{c}6.27 \\
(0.94)\end{array}$ & $1-8$ & & & $.90 * *$ & $.91 * *$ & $.47 * *$ \\
\hline 3. Pathways & $\begin{array}{c}6.22 \\
(1.02)\end{array}$ & $1-8$ & & & - & $.64 * *$ & $.33 *$ \\
\hline 4. Agency & $\begin{array}{c}6.33 \\
(1.07)\end{array}$ & $1-8$ & & & & - & $.53 * *$ \\
\hline 5. ASEScore & $\begin{array}{c}5.33 \\
(0.85)\end{array}$ & $1-7$ & & & & & \\
\hline
\end{tabular}

Note. $N=316$. GPA $=$ grade point average. THScore $=$ Trait Hope Scale. Pathways $=$ pathways subscale. Agency = agency subscale. ASEScore $=$ Academic Self-Efficacy Scale. $* * p<.01 . * p<.05$

To address research question three, a hierarchical regression analysis was conducted for both the THS subscales - agency and pathways - to determine which subscale would be a stronger predictor of a college student's academic achievement. The pathways subscale was the only predictor entered in Model 1, and both the pathways and agency subscales were entered in Model 2. The decision to include pathways first in the model was theory driven, as previous research suggested that the pathways subscale had a greater predicted outcome in academic achievement than the agency subscale (Day et al., 2010).

Our results indicated that Model 1 did not significantly predict academic achievement (self-reported GPA), $F(1,314)=.44, p=.506, R^{2}=.001$. Model 2, with agency scores added, however, significantly accounted for variance in academic achievement, $F(2,313)=19.20, p<$ $.001, R=.331, R^{2}=.109$. Agency as a predictor yielded a larger beta value (standardized $\beta=$ .43 ) compared to pathways (standardized $\beta=-.23$ ) (see Table 2). While pathways and agency 
shared a positive correlation $(r=.63, p<.01)$, they were not overly correlated (i.e., $r>.80$ ), reducing the risk of multicollinearity (Field, 2013). However, pathways had an unexpected negative correlation with the outcome variable: academic achievement in Model 2. This finding indicated a probable suppression effect when the predictor variables (pathways and agency) were significantly and positively correlated with one another, and one of the predictors (agency) was significantly and positively correlated with the outcome variable (GPA), whereas the other predictor variable (pathways) was weakly correlated with the outcome variable (see Model 1). Overall, the results support that there was a statistically significant difference between the strength of agency and pathways in predicting academic achievement among college students. Agency was a stronger predictor of academic achievement in our study.

\section{Table 2}

Hierarchical Multiple Regression Analysis

\begin{tabular}{lcccccc}
\hline & \multicolumn{3}{c}{ Model 1 } & \multicolumn{3}{c}{ Model 2 } \\
\cline { 2 - 7 } Variable & B & $S E B$ & $\beta$ & B & $S E B$ & $\beta$ \\
& & & & & & \\
\hline (Constant) & 3.32 & .14 & & 2.96 & .15 & \\
Pathways & .01 & .02 & .03 & -.09 & 0.28 & $-.23^{* *}$ \\
Agency & & & & .16 & .02 & $.43^{* * *}$ \\
$R^{2}$ & & .001 & & .109 & \\
$F$ for change in $R^{2}$ & & .44 & & $19.20 * * *$ & \\
\hline
\end{tabular}

Note. Pathways = pathways subscale of Trait Hope Scale (THS). Agency $=$ agency subscale of THS.

$* * p<.01 . * * * p<.001$.

For our final research question, we examined whether the association between trait hope and academic achievement would be mediated by academic self-efficacy. Since agency was the only significant and meaningful predictor of academic achievement shown in the regression analysis, we only examined the mediating role of academic self-efficacy in the relationship between the agency subscale and academic achievement. Hayes and Preacher's (2004) PROCESS v3.3 tool was utilized for the mediation analysis. The analysis revealed a statistically significant indirect effect of agency on academic achievement through academic self-efficacy, $b$ 
$=0.09 ;[\mathrm{BC}] 95 \% C I[.056, .123]$ (see Figure 1). When academic self-efficacy was included in the model, the direct effect of agency was no longer statistically significant, which suggests that self-efficacy fully accounted for the relationship between agency and academic achievement. The model with academic self-efficacy as a mediator accounted for approximately $13 \%\left(R^{2}=\right.$ .13) of the variance in academic achievement, which nearly doubled the variance accounted for by the model with only agency $\left(7.7 \% ; R^{2}=.07\right)$ as the predictor. This result was contrary to the results in previous resarch, which found that trait hope had remained a unique and significant predictor of academic achievement, above and beyond the effect of other predictors, including academic self-efficacy (e.g., Feldman \& Kubota, 2015; Gallagher et al., 2017).

\section{Figure 1}

Unstandardized Regression Coefficients from the Multiple Mediation Model Testing the Effects of Agency on Academic Achievement through Academic Self-Efficacy

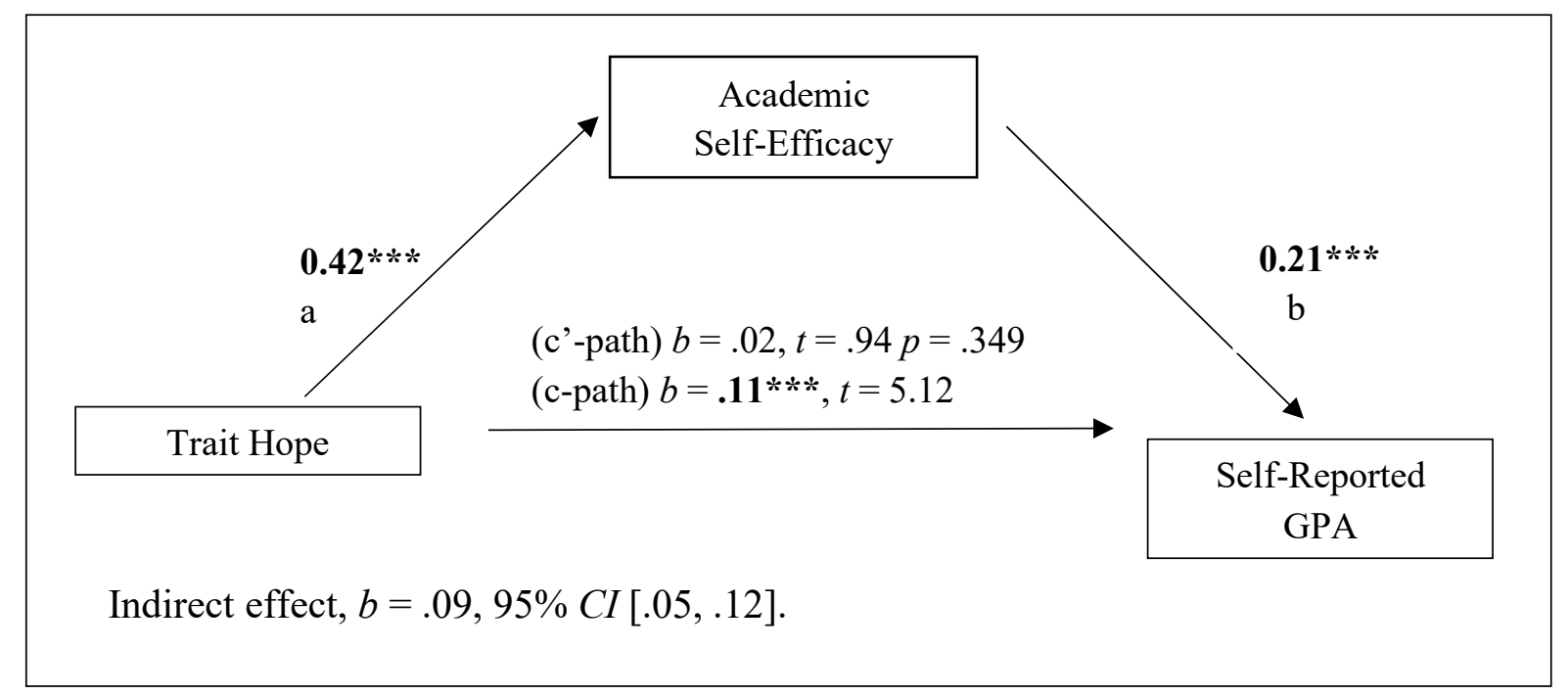

Note. $C=$ total effect of agency and academic self-efficacy on self-reported GPA. $C^{\prime}=\operatorname{direct}$ effect of agency on self-reported GPA. Estimates are based on $N=316$.

To account for the shared associations between agency and the key demographic variables in the model, college-going status, gender, and ethnicity were included as covariates in the mediation analysis. After controlling for the effect of these three covariates, however, the indirect effect of agency on academic achievement through academic self-efficacy remained statistically different from zero $(b=.01, S E=.003,95 \% C I[.01, .02])$, whereas the direct effect of agency was still not statistically significant $(b=.005, p=.34)$ indicating a full mediation 
effect. Since the model with covariates did not yield any different results, we retained the more parsimonious model without the covariates (see Figure 1).

\section{Discussion}

Overall, the findings support our research questions. Trait hope and academic-self efficacy were significantly and positively correlated with academic achievement as measured by self-reported GPA in our study, and academic self-efficacy was a significant mediator in the relationship between agency and academic achievement. Results from our mediation analysis indicate that trait hope may not be as strongly associated with academic achievement as previous research suggested (e.g., Day et al., 2010; Feldman \& Kubota, 2015; Gallagher et al., 2017; Snyder et al., 2002, 2003). Contrary to previous findings (Gallagher et al., 2017), in the present study academic self-efficacy was more strongly correlated than trait hope with academic achievement. The stronger correlation between academic self-efficacy and academic achievement may be, in part, due to the fact that the ASES measures specific beliefs around academic abilities and skills, such as knowing how to study or perform well on tests and believing in one's capacity to conduct academic tasks (Chemers et al., 2001). Trait hope, on the other hand, assesses generalized beliefs about one's ability to achieve goals (agency) and to navigate multiple ways to attain these goals (pathways); thus, trait hope may have a weaker association with specific on-task behavior such as homework completion or performing well on tests, and the subsequent academic outcome measured by GPA. Furthermore, while hope and academic self-efficacy overlap in their attributes, the modest correlation between these two variables in our study suggests that they are ultimately distinct constructs. Future research could examine the differential role of trait hope and self-efficacy in predicting variables related to both the learning process, such as engagement and motivation, and the learning outcomes, such as short-term performance (e.g., test scores) and long-term achievement goals.

Results from our hierarchical regression analysis supported this pattern: agency was a stronger predictor of self-reported GPA. The inverse association between pathways and academic achievement (i.e., the higher the level of pathways, the lower the GPA) seemed counter-intuitive, but it may suggest that pathways acted as a suppressor variable (MacKinnon et al., 2000) due to its lack of relationship with the outcome variable (self-reported GPA) and its significant and positive correlation with agency. The implications of pathways as a suppressor variable would mean that pathways could artificially improve the prediction of academic 
achievement when included in Model 2 simply because pathways was accounting for the variability of agency, the other predictor. It is not likely that pathways actually accounted for the variability in academic achievement since it has a weak, non-significant correlation $(r=.03, p=$ $.25)$ with self-reported GPA in Model 1.

Congruent with past literature, when compared to non-FGCS, FGCS in the present study reported lower GPA and lower internal resources such as hope and academic self-efficacy to succeed academically in higher education (Ishitani, 2006; McDonough, 1997; Padgett et al., 2012). Similar to previous findings (e.g., Chen \& Carroll, 2005; Ishitani, 2006), FGCS in our sample tended to be non-White students: the majority of them (73\%) identified as an ethnic minority or multiracial/multiethnic. Conversely, close to two-thirds (60\%) of continuinggeneration students identified as White. The result is especially prominent given that the present study took place in a small, private, slight majority White institution, and yet non-White participants constitute the majority of the FGCS on campus. Our results also suggest that nonWhite participants reported significantly lower GPA than White participants. The added stress associated with one's ethnic minority status, such as race-based biases, stereotypes, and microaggressions, could exacerbate FGCS' challenges in postsecondary education settings (Ishitani, 2006; Sarcedo et al., 2015).

Finally, our analysis suggests that there was no statistically significant difference in trait hope and academic achievement across gender groups; the only statistically significant gender difference was in academic self-efficacy with male participants reporting a lower score. This result is congruent with previous research by Snyder and colleagues (2002), who found no significant gender differences in trait hope scores and academic achievement. In sum, our results echo some of the previous findings (e.g., Morales, 2009) that first-generation, ethnic minority male students may be especially vulnerable to failure in postsecondary education settings and that formal and informal mentoring efforts should be tailored to this group.

\section{Addressing Limitations through Future Research}

There are several limitations associated with the present study. First, our sample tended to be younger in age. A snapshot approach was used to measure participants' sense of agency, pathways, and self-efficacy. It is possible that they had not had enough time or college-related experience to develop academic specific self-efficacy, resources, and strategies at the time of the survey. Future research could consider a longitudinal design and evaluate how college students' 
trait hope and self-efficacy develop or change over time and how that might be associated with their academic achievement in each successive year.

Second, self-reported GPA was used as the single measure of academic achievement. While self-reported GPA has been shown to be a reliable predictor in prior research (Cassady, 2001), additional indicators of academic success, including standardized test scores and noncognitive skills such as persistence, grit, curiosity, conscientiousness, and social fluidity, can be considered. Furthermore, future research could examine the differential roles of trait hope and academic self-efficacy in predicting variables related to both the learning process, such as engagement and metacognition, as well as learning outcomes, such as short-term performance (e.g., examination scores) and longer-term achievement (e.g., GPA, retention, graduation). Finally, our sample was drawn from a private, slight majority White institution with majority female students; thus, the findings may not generalize to college students attending universities with a very different demographic composition. Future studies could extend the applicability of the current model with trait hope and self-efficacy in predicting academic success among a student population more diverse in ethnicity, gender, age, and ability.

\section{Implications for Practice and Intervention}

One of the most important findings gleaned from this study is that both general attitude/motivation and specific academic abilities and skills are critical to college success. This finding supports previous research by Gallagher et al. (2017) that while hope and academic selfefficacy were both correlated to achievement and retention, perceived academic abilities uniquely predicted academic achievement. Similarly, Robinson and Rose (2010) found that academic specific measures of hope were more predictive of academic achievement than the general trait hope. While instilling general beliefs of hopefulness in college students is important, without specific academic support and guidance in the postsecondary setting, students may not know how to realize their potential and reach their academic goals. Students need to believe that they can succeed academically, but they also need to be equipped with tools. Therefore, hope interventions should be coupled with academic self-efficacy efforts. Interventions for pre-college and college students should be focused on academic specific beliefs and skills in relation to overall achievement (e.g., Ma \& Shea, 2021 Shea et al., 2007). This application is especially critical for FGCS who tend to be less academically prepared and to endorse lower hope and lower self-efficacy than continuing-generation students. FGCS can benefit from academic 
specific support and agency related interventions to increase academic achievement. Those interventions could include specific scholastic instruction, academic counseling, and social networking support to enhance their capacity as learners (Snyder et al., 2003). Counselors can provide academic specific support as well as foster hope through encouraging opportunities for students to experience mastery of goals, in order to increase their experiences with successful goal pursuits to strengthen agency for future goal initiation and pursuits (Snyder et al., 2002).

Research has also suggested that FGCS are at risk of failure in the postsecondary setting due to their lack of cultural capital for effectively navigating the education system (Ishitani, 2006; McDonough, 1997; Padgett et al., 2012). In addition to skills building, FGCS would benefit from formal and informal counseling, mentoring, and social support that helps them identify resources and gain access to academic and career opportunities (Morales, 2009). Mentors and role models - especially those from the similar immigrant and ethnic background as the FGCS - not only provide professional and academic knowledge to enhance FGCS' cultural capital, but they can also help FGCS develop long-term positive social relationships (McDonough, 1997; Morales, 2009; Padgett et al., 2012) and promote FGCS' sense of belonging and connectedness to campus (Ma \& Shea, 2021). All of these strategies are likely to increase the likelihood of FGCS' academic resilience and success in the postsecondary setting.

Finally, family partnerships in pre-college and college interventions, especially among FGCS and other at-risk groups, are expected to yield more hopeful academic outcomes (Martinez, 2003; Padgett et al., 2012). In summary, the results from the present study suggest that academic specific self-efficacy and support are especially important to overall academic achievement. For FGCS, without knowing how they can succeed academically, a general belief that they can succeed in college is limited in its effect. 


\section{References}

Atik, G., \& Zeynep, E., (2017). Predicting hope levels of high school students: The role of academic self-efficacy and problem solving. Education \& Science/Egitim ve Bilim 42(190), 157-69. http://dx.doi.org/10.15390/EB.2017.5348

Bandura, A. (1977). Self-efficacy: Toward a unifying theory of behavioral change. Psychological Review, 84(2), 191-215. https://doi.org/10.1037//0033-295x.84.2.191

Cassady, J. C. (2001). Self-reported GPA and SAT scores. (ED458216). ERIC. https://eric.ed.gov/?id=ED458216

Cataldi, E. F., Bennett, C. T., \& Chen, X. L. (2018). First-generation students: College access, persistence, and postbachelor's outcomes. National Center for Education Statistics.

Chemers, M. M., Hu, L., \& Garcia, B. F. (2001). Academic self-efficacy and first-year college student performance and adjustment. Journal of Educational Psychology, 93(1), 55. https://doi.org/10.1037/0022-0663.93.1.55

Chen, X. (2005). First Generation Students in Postsecondary Education: A Look at Their College Transcripts (NCES 2005-171). U.S. Department of Education, National Center for Education Statistics. Washington, DC: U.S. Government Printing Office.

Cohen, J. (1992). A power primer. Psychological Bulletin, 112(1), 155-159. https://doi.org/10.1037//0033-2909.112.1.155

Day, L., Hanson, K., Maltby, J., Proctor, C., \& Wood, A. (2010). Hope uniquely predicts objective academic achievement above intelligence, personality, and previous academic achievement. Journal of Research in Personality, 44(4), 550-553. https://doi.org/10.1016/j.jrp.2010.05.009

Feldman, D. B., \& Kubota, M. (2015). Hope, self-efficacy, optimism, and academic achievement: Distinguishing constructs and levels of specificity in predicting college grade-point average. Learning \& Individual Differences, 37, 210-216. https://doi.org/10.1016/j.lindif.2014.11.022

Field, A. P. (2013). Discovering statistics using SPSS: And sex and drugs and rock ' $n$ ' roll (4th ed.). SAGE.

Gallagher, M. W., Marques, S. C., \& Lopez, S. J. (2017). Hope and the academic trajectory of college students. Journal of Happiness Studies, 18(2), 341-352. https://doi.org/10.1007/s10902-016-9727-z 
Gilman, R. G., Dooley, J., \& Florell, D. (2006). Relative levels of hope and their relationship with academic and psychological indicators among adolescents. Journal of Social \& Clinical Psychology, 25(2), 166-178. https://doi.org/10.1521/jscp.2006.25.2.166

Hayes, A. F., \& Preacher, K. J. (2004). Statistical mediation analysis with a multicategorical independent variable. British Journal of Mathematical \& Statistical Psychology, 67(3), 451-470. https://doi.org/10.1111/bmsp.12028

Hussar, B., Zhang, J., Hein, S., Wang, K., Roberts, A., Cui, J., Smith, M., Bullock Mann, F., Barmer, A., and Dilig, R. (2020). The Condition of Education 2020 (NCES 2020-144). U.S. Department of Education. Washington, DC: National Center for Education Statistics. https://nces.ed.gov/pubsearch/pubsinfo.asp?pubid=2020144

Ishitani, T. T. (2006). Studying attrition and degree completion behavior among firstgeneration college students in the United States. Journal of Higher Education, 77(5), 861-885. https://doi.org/10.1353/jhe.2006.0042

Jehangir, R. R. (2010). Higher education and first-generation students: Cultivating community, voice and place for the new majority. Palgrave Macmillan Press.

Ma, P. W., \& Shea, M. (2021). First-generation college students' perceived barriers and vocational outcome expectations: Exploring the role of relational factors and sense of coherence. Journal of Career Development, 48(2), 91-104. https://doi.org/10.1177/0894845319827650

MacKinnon, D. P., Krull, J. L., \& Lockwood, C. M. (2000). Equivalence of the mediation, confounding and suppression effect. Prevention Science, 1(4), 173-181. https://doi.org/10.1023/A:1026595011371

Marques, S. C., Gallagher, M. W., \& Lopez, S. J. (2017). Hope- and academic-related outcomes: A meta-analysis. School Mental Health, 9(3), 250-262. https://doi.org/10.1007/s12310-017-9212-9

Martinez, M. D. (2003). Missing in action: Reconstructing hope and possibility among Latino students placed at risk. Journal of Latinos and Education, 2(1), 13-21. https://doi.org/10.1207/S1532771XJLE0201_3

McDonough, P. M. (1997). Choosing college: How social class and schools structure opportunity. SUNY Press. 
Morales, E. E. (2009). Legitimizing hope: An exploration of effective mentoring for Dominican American male college students. Journal of College Student Retention: Research, Theory and Practice, 11(3), 385-406. https://doi.org/10.2190/CS.11.3.e National Center for Education Statistics. (2019). Graduation rate from first institution attended for first-time, full-time bachelor's degree-seeking students at 4-year postsecondary institutions, by racelethnicity, time to completion, sex, control of institution, and percentage of applications accepted: Selected cohort entry years, 1996 through 2012. https://nces.ed.gov/programs/digest/d19/tables/dt19_326.10.asp

Padgett, R. D., Johnson, M. P., \& Pascarella, E. T. (2012). First-generation undergraduate students and the impacts of the first year of college: Additional evidence. Journal of College Student Development, 53(2), 243-266. https://doi.org/10.1353/csd.2012.0032

Rao, M. A., \& Donaldson, S. I. (2015). Expanding opportunities for diversity in positive psychology: An examination of gender, race, and ethnicity. Canadian Psychology, 56(3), 271-282. https://doi.org/10.1037/cap0000036

Robinson, C., \& Rose, S. (2010). Predictive, construct, and convergent validity of general and domain-specific measures of hope for college student academic achievement. Research in the Schools, 17(1), 38-52. https://psycnet.apa.org/record/2011-23901-006

Sarcedo, G. L., Matias, C. E., Montoya, R., \& Nishi, N. (2015). Dirty dancing with race and class: Microaggressions toward first-generation and low-income college students of color. Journal of Critical Scholarship on Higher Education and Student Affairs, 2(1), 1-17. https://ecommons.luc.edu/jcshesa/vol2/iss1/1

Shea, M., Ma, P. W., \& Yeh, C. J. (2007). Development of a culturally specific career exploration group for urban Chinese immigrant youth. The Career Development Quarterly, 56(1), 62-73. https://doi.org/10.1002/j.2161-0045.2007.tb00020.x

Snyder, C. R., Harris, C., Anderson, J. R., Holleran, S. A., Irving, L. M., Sigmon, S., \& Harney, P. (1991). The will and the ways: Development and validation of an individual-differences measure of hope. Journal of Personality \& Social Psychology, 60(4), 570-585. https://doi.org/10.1037/0022-3514.60.4.570

Snyder, C. R., \& Lopez, S. J. (2005). Handbook of positive psychology. Oxford University Press. 
Snyder, C. R., Lopez, S. J., Shorey, H. S., Rand, K., \& Feldman, D. B. (2003). Hope Theory, measurements, and applications to school psychology. School Psychology Quarterly, 18(2), 122-139. https://doi.org/10.1521/scpq.18.2.122.21854

Snyder, C. R., Shorey, H. S., Cheavens, J., Pulvers, K. M., Adams, V. I., \& Wiklund, C. (2002). Hope and academic success in college. Journal of Educational Psychology, 94(4), 820826. https://doi.org/10.1037/0022-0663.94.4.820

Snyder, T. D., de Brey, C., \& Dillow, S. A. (2019). Digest of education statistics 2017 (53 ${ }^{\text {rd }}$ ed.). U.S. Department of Education. https://nces.ed.gov/pubs2018/2018070.pdf

Strayhorn, T. L. (2010). When race and gender collide: Social and cultural capital's influence on the academic achievement of African American and Latino males. The Review of Higher Education, 33(3), 307-332. https://doi.org/10.1353/rhe.0.0147

Tate, K. A., Caperton, W., Kaiser, D., Pruitt, N. T., White, H., \& Hall, E. (2015). An exploration of first-generation college students' career development beliefs and experiences. Journal of Career Development, 42(4), 294-310. https://doi.org/10.1177/0894845314565025 